Torabi Haghighi, A., Sadegh. M, Behrouz Kohenjani, S., Hekmat zadeh, A.K., Karimi, A., Kløve, B., 2019, Mirage water concept and an index-based approach to quantify causes of hydrological changes in semi-arid regions, Hydrological Science journal, In press. https://doi.org/10.1080/02626667.2019.1691728 (1)

\title{
The mirage water concept and an index-based approach to quantify causes of
}

\section{hydrological changes in semi-arid regions}

Ali Torabi Haghighi ${ }^{*}$, Mojtaba Sadegh ${ }^{2}$, Siavash Behrooz-Koohenjani ${ }^{3}$, Ali Akbar Hekmatzadeh $^{4}$, Akbar Karimi $^{5}$ and Bjørn Kløve ${ }^{1}$

${ }^{1}$ Water, Energy and Environmental Engineering, Faculty of Technology, 90014 University of

Oulu, Finland

${ }^{2}$ Department of Civil Engineering, Boise State University, Boise, ID 83725, USA.

${ }^{3}$ Iranian Water Resources Management Company, Fars Regional Water Authority, Eram Blvd. Shiraz, Iran.

${ }^{4}$ Department of Civil and Environmental Engineering, Shiraz University of Technology, Shiraz, Iran.

${ }^{5}$ Built \& Natural Environment, Caledonian College of Engineering, Muscat, Sultanate of

Oman

*Correspondence to: Ali Torabi Haghighi, Water Energy Environmental Engineering Unit, Faculty of Technology, 90014 University of Oulu, Finland; email: ali.torabihaghighi@oulu.fi

Abstract.

In semi-arid regions, reduced river flows due to expanding irrigation for agriculture lead to reduced inflow to dams and reservoirs over time. This is a major challenge in water resources 
management for water supply, irrigation and hydropower. To better address changes in runoff, and to separate naturally occurring drought from water consumed by agriculture, we present a new Standardized Rainfall to Runoff Index (SCRI) for evaluating changes in rainfall contribution to flow in river systems. We employ the Standardized Precipitation Index (SPI), Standardized Discharge Index (SDI) and Standardized Rainfall-Runoff Index (SCRI) to characterize meteorological drought, hydrological drought and land use change impacts on river flow, respectively. These indices are applied to the Mond river (the fifth longest river in Iran) basin, which has been regulated by the Salman Farsi and Tangab dams since 2006. The results clearly show a significant negative trend in SCRI at the basin outlet. The analysis reveals new hydrological conditions with reduced flow (by $25-45 \%$ depending on location) due to construction of small structures for aquifer recharge and flood control that has led to increased water consumption upstream. Our analysis showed no marked impact of climate variability in the region for the period studied. Finally, we propose a new concept called "mirage water" that represents the reduced water delivery to downstream areas due to new developments and water withdrawals in headwater tributaries. In particular, mirage water accounts for changes in upstream water consumption between the planning phase and construction/operation life of dams. We recommend that this concept be used for communication with decision makers and managers to clarify the need for revising dimensions of planned dams.

Key words: Land use change, hydrological changes, anthropogenic drought, Mond river basin.

\section{Introduction}


In arid and semi-arid regions, drought and water shortage limit agricultural development (Oweis 2005). Consequently, dam construction, deep well drilling and development of irrigation practices are used to support increased water consumption and agricultural production. Water use in agriculture accounts for more than $75 \%$ of water consumption worldwide (Oweis 2005, Biswas 2007, Nikouei and Ward 2013, Oweis 2005). Although the use of surface water is a higher priority for water resources decision makers, farmers often favour groundwater (GW) because it is locally available, shows less spatial variation to surface water (SW), requires minimal conveyance structures and often relaxes the need for long planning horizons. These advantages come at the expense of higher power costs. All factors considered, GW is a secure resource, provides self-sufficiency and offers an attractive alternative for irrigation in semi-arid and arid regions (Al-Senafy and Abraham 2004, Ambast et al. 2006, Giordano and Villholth 2007, Van Camp et al. 2010). Indeed, GW-based irrigation produces $40 \%$ of the world's food (Morris et al. 2003). A recent trend in many catchments is that more GW is being used (Molina et al. 2011), partly uncontrolled and through illegal wells to support water-intensive crops and expanded cropland area (Ruprez-Moreno et al. 2017). GW overexploitation is exacerbated by the competitive behaviour of farmers (Soltani and Saboohi 2008, Yu et al. 2017).

GW overuse, due to the myopic behaviour of farmers, leads to unsustainable water resource consumption. Long-term overexploitation of GW resources has directly and significantly reduced river base flow and soil moisture in many regions around the globe (Zaki et al. 2019). In addition, when the economy of communities and farmers depends on irrigation with GW, any sign of GW depletion triggers anxiety and panic about future water security. This leads to local and regional efforts to use available surface water for artificial recharge of exhausted aquifers during the wet season, by beneficiaries and even governments. Thus, declining surface water and consequently hydrological drought downstream (which often also experiences high GW consumption) can occur without any signal of meteorological drought in the area. 
Reduction in river flow regimes has been observed in many regions due to expansion of agriculture, but particularly in arid and semi-arid regions (Sadegh et al. 2010, Fazel et al. 2017, Torabi Haghighi and Kløve 2017).

The main purpose of this study was to assess hydrological change beyond climatological variability by using available indicators and to develop a new index and propose a new concept. Increasing water use in headwater regions could decrease the contribution of upstream flow to downstream dams, which could lead to increased uncertainty in operation of dams and eventually failure to achieve their intended purposes. Using past hydrological records with a stationary assumption of rainfall-runoff processes for design may result in oversized dams, wasted investment and failure to satisfy planned beneficiaries. In these catchments with increased headwater irrigation, the recurrence of low hydrological extremes (hydrological drought) can be more frequent and even stronger than low climatological extremes (meteorological drought), while in natural conditions the flow fluctuation typically smoothly follows the climatological signal. To compare hydrological droughts and natural and/or anthropogenic droughts, we used the standardized precipitation index (SPI, e.g. McKee et al. 1993) and Standardized Discharge Index (SDI, e.g. Shukla and Wood, 2008) and devised another index, Standardized Contribution of Rainfall to runoff Index (SCRI), as hydrological and land use change indices.

In the present work, we introduce a new concept called "mirage water" as the amount of water that was accounted for in the water management planning phase but is no longer available in the operation phase. Better understanding of changes in dam inflow is essential to optimise dam operations, or to inform future dam planning, design and construction. The loss of water is due to the new developments and water consumption in the headwater tributaries. We use as a case study the Mond, a major river discharging to the Persian Gulf, south-central Iran. This catchment has been and is planned to be modified by many dams with high investment costs, 
despite a significant decline in river flow due to anthropogenic activity before the start of dam operation, questioning the concept of stationarity currently used in dam design.

\section{Mond River Basin}

The Mond River is the fifth longest river (617 km in length) in Iran and the most important river in the central part of the Persian Gulf basin. It is the main source of surface water for a large region in southern Iran. Mond River has three major tributaries: Qare-Aqaj (QA), Shoor-eJahrom (SJ) and Shoor-e-Firouzabad (SF) that run in the centre, eastern and western part of the basin, respectively. It also has two large ephemeral rivers (Kurdeh and Alamarvdasht) which drain the eastern part of the basin (Fig. 1a). The basin occupies an area of $47802 \mathrm{~km}^{2}$ and extends through Fars and Bushehr provinces in southern Iran (Fig. 1). Basin climate varies from hot and arid in the south to sub-humid and cold in the north (Fig. 1b). Mean annual rainfall varies from $172 \mathrm{~mm}$ at Dezhgah in the south to $1044 \mathrm{~mm}$ at Bonroud in the north-west, and mean annual temperature varies from $14{ }^{\circ} \mathrm{C}$ at Dasht-e-Arzhan in the north-west to $26{ }^{\circ} \mathrm{C}$ at Qantareh in the south (Azari Dehkordi 2011) [Figure 1 near here].

The Mond River is a strategic source of water for southern Iran, a region that is economically important due to its gas and oil reserves. Due to the temporal and spatial variation in surface water availability, construction of five storage dams with considerable investment has been planned to optimise the exploitation of river flow in the entire basin. The Mond River has been modified since 2006 by the Salman Farsi dam $\left(1.6 \mathrm{~km}^{3}\right)$ on the main river and the Tangab dam $\left(0.23 \mathrm{~km}^{3}\right)$ on its SF tributary. The process of river modification is continuing with construction of four more dams, Kavar, Haiqer, Dashte Pelqang and Baqan (Fig. 1a). 
The livelihood of most inhabitants of Fars province, including those of the Mond river basin, is crucially dependent on available water resources, since agriculture is the major and traditional source of income in the region. About 180 productive fields with a surface area of about 48000 $\mathrm{km}^{2}$ (Hojjati and Boustani 2010) make Fars one of the major agricultural districts in Iran. The Bande-Bahman diversion dam is one of the oldest operating hydraulic structures in Iran, as it was constructed on the Qare-Aqaj River about 1700 years ago. Except for some adjacent areas at the river margin that are supplied by the Bande-Bahman dam, and some other minor diversion dams, the majority of agricultural production in the region is supported by GW. According to Mond water resources atlas, total water withdrawal in the Mond basin is $2.67 \mathrm{~km}^{3}$, which is mainly provided by GW (more than $1.96 \mathrm{~km}^{3}$ ), and agriculture, using $93.8 \%$, is the dominant water consumer in this basin (Azari Dehkordi 2011). According to the agricultural census, Fars province has the greatest area of arable crops in Iran, with a significant increase (about 7-fold) in cultivated area between 1972 (60,800 ha) and 2016 (407,228 ha). The Mond basin hosts 25$30 \%$ of the total area of permanent crops in Fars province and is the main producer of citrus fruits and dates (Agriculture census 1972-2016). Regarding annual crops, the cultivated area increased from 511,000 ha in 1972 to 119,345 ha in 2006 , and then decreased to 713,000 ha in 2015, with about 20\% of annual crops cultivated in the Mond basin (SCI 1973, MAJ 2007, MAJ 2017). Declining GW level due to overabstraction is a major concern in the Mond basin and Fars province (Torabi Haghighi and Keshtkaran 2007).

Due to significant GW withdrawal for irrigation (annually $6.7 \mathrm{~km}^{3}$, about $70 \%$ of which is consumed in the agricultural sector) (Hojjati and Boustani, 2010), the GW level in the major aquifers of the region has dramatically declined. Six vivid examples are GW declining in Fasa, Firozabad, Jahrom, Qarebolaq and Afzar plains in the Mond basin, and in Shiraz and Darab plains in adjacent basins (Fig. 2b). After alarming GW depletion, most beneficiaries (farmers) 
have started efforts to revive GW storage. More than 500 embankments are already installed, under construction or planned for artificial GW recharge in Fars province (Fig. 2a). The embankments distribute floods on the land for artificial recharge (Soil and Water Subgroup, 2004).

[Figure 2 near here]

For analysis of meteorological drought in the present study, monthly rainfall data from 26 stations that have reliable data for 1971-2006 were selected from inside and outside the Mond basin (Fig. 1a). For flow regime analysis and assessment of hydrological drought, the basin was divided into seven sub-basins based on the availability of flow data for 1971-2006 (seven gauges in Fig. 1a). Among the selected gauge stations, Qantareh (station no. 1), which is the last gauge on the Mond river before discharging into the Persian Gulf, Tang-e-Karzin (station no. 2), which is placed below the Salman Farsi dam, Bande-Bahman station (station no. 4), which is placed below Kavar dam, and Tangab (station no. 6), which is placed below the Tangab dam, were deemed the most important points for this study, as they reflect the consequences of land use change on basin outflow and inflow to two major dams before operation. The names and information on discharge gauges and climatological stations are provided in supplementary material (Tables S1 and S2 in Supplementary material).

We selected 2006 for two reasons: i) major river modifications and dam constructions have been done after 2006 and therefore hydrological change in the lower part of the basin after 2006 is evident and predictable, ii) the period 2006-2014 was dominated by meteorological drought (as shown in the supplementary material), so any hydrological deficit detected in this period would be attributed to meteorological drought, while we intended to show the hydrological deficit in the basin before 2006, and possible dysfunctionality in operation of dams due to this change. 


\section{Methodology}

174

175 Spatial, temporal and trend analysis were carried out to evaluate the variability of precipitation,

176 flow and the contribution of rainfall to observed runoff in the Mond river basin during 1971-

1772006.

\subsection{Drought Trend and SPI, SDI and SCRI Analysis}

180

To analyse the spatiotemporal hydro-climatological status of the Mond basin, the trend and variation, as well as the average value, in rainfall, discharge and contribution of rainfall to runoff were calculated. The Mann-Kendall (M-K) test was used to evaluate trends in these parameters (Gilbert 1987, Kendall 1975, Mann 1945). It is a simple, robust and widely used method to detect upward or downward trends in a variable over time in different fields of environmental science.

Temporal and spatial climate variability were evaluated using the Standardized Precipitation Index (SPI), which is designed to evaluate metrological drought (McKee et al. 1993, McKee et al. 1995) and has been widely used for evaluating climate variability (Irannezhad et al. 2014, Hao et al. 2014). Parametric SPI requires fitting a gamma probability density function (Edwards and McKee 1997, Thom 1966) to the frequency distribution of precipitation at a given station for a particular time scale (e.g. 3 months, 6 months etc.). SPI is then estimated as (Farahmand and Aghakouchak 2015):

$\mathrm{SPI}=\emptyset^{-1}(p)$ 
where $\varnothing$ is the standardised normal distribution function and $p$ is the corresponding empirical probability when the data are sorted in ascending order. Based on SPI, climate conditions can be divided into eight categories as classified in Table 1 [Table 1 near here]. As multiple variables (including discharge and contribution of rainfall on runoff) are used to describe various drought categories, we used a generalised framework for generating spatially and temporally consistent drought indicators based on nonparametric standardised multivariate indices (Farahmand and Aghakouchak 2015). Parametric approaches are associated with uncertainties in (1) selection of the distribution to fit the data and (2) posterior distribution of the model parameters (Sadegh et al. 2018; Mallakpour et al. 2019). These issues do not influence the non-parametric drought indices.

Over time, increased water consumption typically occurs in the upstream part of many basins. Increasing water exploitation or land use change in the upstream part could significantly change the contribution of rainfall to runoff in the river basin, and subsequently reduce (or enhance, e.g. if urbanisation occurs) water delivery to the downstream. To evaluate the possible link between rainfall and discharge variation, we used the Standardized Discharge (Runoff) Index (SDI) (Shukla and Wood, 2008). To evaluate the variation in rainfall contribution to runoff, a novel index (SCRI), inspired by the SPI and SDI methodology, is introduced here. In SCRI, we replace rainfall in the SPI method with contribution of rainfall to runoff (CR). We use the same description for the different classes of SPI (Table 1) for the SDI variation. For calculating CR in the SCRI index, in each year we define the period of maximum rainfall as 1-6 months. For that period (1-6 months), the contribution of rainfall CR to runoff for each contributing area that has a gauge at the end of basin is calculated as (dimensionless):

$\mathrm{CR}=\frac{F}{P}$

where $P(\mathrm{~mm})$ and $F(\mathrm{~mm})$ are the height of rainfall and runoff for the study period, respectively, and: 
220

221

where $A\left(\mathrm{~m}^{2}\right)$ is the area of sub-basin that drains to the selected gauges used to calculate $\mathrm{R}, Q_{B}$ $\left(\mathrm{m}^{3} \mathrm{~s}^{-1}\right)$ is base flow, $Q\left(\mathrm{~m}^{3} \mathrm{~s}^{-1}\right)$ is the average flow rate during the selected period (1-6 months), 86400 is the conversion factor from days to seconds and $n$ (day) is the number of days in the study period. To define $Q_{B}$, we use the linear interpolation between the discharge in the river for a month before and a month after the selected period.

To calculate rainfall for sub-basin which is placed in upstream of each gauge in the Mond basin, we performed spatial analysis of rainfall by considering all available rainfall stations across the basin or in adjacent areas, using code developed in MATLAB (Fig. S1 in supplementary material). In spatial analysis, the polygon of basin (the area upstream of a gauge; Fig. Sup1a in supplementary material) is circumscribed by a meshed rectangle (Fig. S1b in supplementary material). Using the available "scattered Interpolant" function in MATLAB, we produced a time series of interpolating function ("F") based on 26 climate stations (Eq. 4) for each single time sequence (here we used monthly data).

$F_{t}=$ scatteredInterpolant $(\mathrm{X}, \mathrm{Y}, \mathrm{P}(\mathrm{t}))$

where $\mathrm{X}$ and $\mathrm{Y}$ are the longitude and latitude of each of the 26 stations and $\mathrm{P}(\mathrm{t})$ is relevant rainfall value at time t. The rainfall for each mesh point inside the rectangle was calculated as:

$P_{\left(\text {at } X_{\text {mesh }}, Y_{m e s h} \text { and } t\right)}=F_{t_{\left(X_{m e s h}, Y_{m e s h}\right)}}$

We then found those meshes placed inside the area of interest (polygon of sub-basin, part $\mathrm{d}$ in Fig. 4). Mean value of calculated rainfall for these inside meshes was considered mean rainfall of the area of interest for time $t$. It is worth noting that the "scattered Interpolant" is a MATAB function that let us define the scatter points in terms of $\mathrm{X}, \mathrm{Y}, \mathrm{Z}$ (here precipitation at each station), then estimate the value of $\mathrm{Z}$ (here precipitation) at any arbitrary point (here our grades 
across the area of seven sub-basins for desired gauges). More information regarding the "scattered Interpolant" method can be found on the Mathworks website (Mathworks 2019).

\section{Results}

\subsection{Spatiotemporal Variability in Rainfall in the Mond Basin}

Based on precipitation records from 1971-2006, the maximum 1-, 2-, 3-, 4-, 5- and 6-month rainfall occurs in November-April (Fig. 3A1 and 3A2). Since more than 95\% of rainfall (Fig. 3A1) occurs during this period, November-April can be classified as the 'wet season'. Monthly and seasonal trend analysis in the whole basin showed no significant trend (at 95\% confidence level) in rainfall (Fig. 4a and Fig. S10 in the supplementary material), except for September and October (Fig. 4a1 and 4a12), which showed a positive trend at $\mathrm{p}_{\mathrm{Val}}=0.042$ and $\mathrm{p}_{\mathrm{Val}}=0.017$. However, the contribution of these months (September and October) to annual rainfall was less than $1 \%$, so this increasing trend did not play a significant role for the magnitude of total accessible water in the Mond basin. Spatial analysis also showed no significant trend in annual rainfall in different sub-basins, but the north-west part of the basin showed some minor increase.

[Figures 3 and 4 near here]

The spatiotemporal climate analysis (based on SPI) revealed that the spatial distribution of SPI was uniform over the entire basin during $61 \%$ of the years (Fig. 5). Extreme 1-, 3- and 5-year continuous droughts occurred during December 1983-November 1984 (extreme drought), April 1982-March 1984 (extreme drought) and December 1981-November 1985 (severe drought) (Fig. 6a). The wettest climatological periods were observed in 1994 (extremely wet), 1994-1996 (extremely wet) and 1991-1995 (mildly wet), for 1-, 3- and 5-year periods, respectively (Figs. 5 and 6). 
267

268

The SPI is the standardized rainfall anomaly index and is widely used for meteorological drought assessment with categories for wet and dry conditions (Table 1) (Lloyd-Hughes and Saunders 2002; Angelidis et al. 2012). For the Mond river basin, the 12-month SPI was classified as mild drought or mildly wet for $33.3 \%$ and $30.5 \%$ of years, respectively. This means that in $63.9 \%$ of years the Mond basin, climate conditions fall into these two categories. We propose that some parts of these two classes be removed (we suggest SPI between -0.5 and 0.5 ) to make a new class 'normal conditions'. Agnew (2000) suggested a "no drought" category when the SPI varied from -0.5 to 0 , while some other works (e.g. Montaseri et al. 2017) define a "near normal" category when the SPI varies from -1.0 to 1.0. According to the categories proposed by McKee et al. (1993) (Table 1), 53\% and 47\% of years in the Mond river basin are in meteorological drought and wet conditions, respectively. Based on this new category (Table 1, columns 3 and 4), the Mond basin has been faced with normal (SPI varying from -0.50 to 0.50), drought and wet climate conditions in $39 \%, 28 \%$ and $33 \%$ of whole years, respectively, which are more reasonable categories to describe the conditions.

\subsection{Hydrological Changes in the Mond River and its Tributaries}

The analysis of river flow records from 1971 to 2006 showed that most of the river discharge (about 95\% mean annual flow) occurred in the wet season (December-May), with a fast response to rainfall (Fig. 3B1). The base flow was low in late spring and summer. During all months, the outflow from the basin at the lower part (Qantareh gauge) decreased, but only showed a significant negative trend in the periods June-November (Fig. 4 and Fig. S18 in the supplementary material). As shown before, the flow in the river during these months (dry 
season) is usually supported by base flow. In contrast to the major part of the basin, the northeast part (Shoor-Jahrom tributary; Fig. 1b) showed increasing flow during the June, July, September and October (Fig. 4b, and Fig. S12 in the supplementary material), with a significant trend.

During 36\% of the whole period, all eight stations showed uniformly negative SDI (e.g. 1982, 1998, 1999 in Fig. 5) or positive SDI (e.g. 1970, 1974, 1978, 1991 in Fig. 5, Fig.6). Based on the SDI at the basin outlet (Qantareh station), the driest periods for the Mond river occurred during 2000, 1999-2002, 1999-2003, 1999-2006 and 1996-2005, while the wettest periods were 1985-1986, 1985-1988, 1971-1976 and 1971-1978 (Fig. 5 and Fig. 6). Overall, these results clearly show that the hydrological drought recurrence is increasing over time, as the wettest period was observed before 1971-1988 and the driest period after 1996.

\subsection{Contribution of Rainfall to Discharge in the Mond Basin}

During more than $75 \%$ of the selected period (1971-2006), more than 90\% of rainfall (Fig. 3A1 and 3A3) occurred during five months (November-March) or less (Fig. 3A2). This shows a significant seasonal regime for the Mond river, since more than $80 \%$ of the flow at Qantareh gauge (Fig. 3B1 and 3B3) occurred during these five months (Figs. 3A2 and 3B2). With increasing rate of monthly rainfall (e.g. 1971-80) from November to January (Fig. 7b) in the basin, the flow also increased (Fig. 7b). In January (1971-80), there was maximum rainfall in the basin and maximum runoff in the river (Figs. 7a and 7b). With decreasing rainfall in March, a fall in the rate of flow was observed (Figs. 7a and 7b). In the second period (1980-88), maximum rainfall and flow were observed in December and a reduction in rainfall in January and February, seen as reduction in flow in the latter months (Fig 7b). In March, with increasing rainfall, the magnitude of flow increased. The annual variation in flow directly followed the annual rainfall variability (e.g. at Qantareh gauge; Fig. 3A2 and 3B2, Fig. 7a and 7b). Therefore, 
we were able to confirm that the majority of the direct contribution of rainfall to flow occurs during the wet season. Thus, we calculated the contribution of rainfall to runoff ( $R$ and SCRI in Eq. 7) for the 1-6 month period (Fig. 7c and 7d). A clear reduction in the contribution of rainfall to flow in the whole basin was seen in the four different continuous quarters of the study period (1971-2006). The second period had the lowest rainfall magnitude (the lowest 10-year SPI also occurred during 1980-1989), but the lowest amount of flow discharged to Persian Gulf in 1997-2006 (Fig. 7a1 and 7a2). The contribution of rainfall to flow (R, Eq. 2) for the whole basin (based on the long-term flow at Qantareh gauge) showed a significant negative trend for 1-6 month periods (Fig. 7c1-7c6). Among the first 12 years, only three had negative SDI or hydrological drought (1971, 1972 and 1979) at the last station in the basin (first two rows in Fig. 5), while in the second and third 12-year periods the number of negative SDI increased to 7 and 9, respectively (Fig. 5). According to the SPI value, 1980 and 2000 were more or less similar (close to 0), but the SDI value at the basin outlet was positive for 1980 and negative for 2000 (Fig. 5). This reduction in the contribution of rainfall to inflow could be beyond climate variability, and is probably due to the compounding effects of several factors such as changes in land use, increases in water consumption, flood control projects, watershed management and managed aquifer recharge projects in the headwaters [Figure 7 near here].

\subsection{Hydrological and Metrological Drought in the Mond Basin}

Over time the intensity of hydrological drought increased. To illustrate this fact, we developed a time series of difference between SPI and SDI (Fig. 5). In early years SPI exceeded SDI, while in last few years SDI has come to exceed SPI (Fig. 5). During 1971-1988 (first half of the study), $52 \%$ and $42 \%$ of the period was below the metrological and hydrological drought threshold, respectively, and showed more metrological than hydrological drought. These percentages changed to $48 \%$ and $58 \%$, respectively (more hydrological drought) for 1989-2006 (Fig. 6b). For the period 1970-2006, all extreme metrological droughts for different sequences (6 months- 
10 years) occurred before 1990, while the major hydrological droughts were observed in recent years and the second half of the study period (Fig. 6a). The temporal flow reduction in river discharge might have two main reasons, natural (meteorological drought due to decreasing rainfall) and/or anthropogenic effects. During the second period of analysis (1989-2006), a reduction in hydrological drought was expected, since the percentage of metrological droughts was reduced (from 52\% to 48\%). However, increasing percentage of hydrological droughts (from $42 \%$ to $58 \%$ ) was actually observed (Fig. 6b). Consequently, we attribute the recent hydrological droughts to anthropogenic activities, rather than climate variability. This is also clearly evident in the reduction in the contribution of rainfall to flow at Qantareh station (Fig. 6b), increasing the number of years with negative SCRI from 39\% (for 1971-1988) to 62\% (for 1989-2006).

The occurrence times of extreme points of SPI, SDI and SCRI were asynchronous (Fig. 8). To show this issue, the rank of each index (in ascending or descending order for minimum and maximum respectively) was found for the occurrence time of the maximum and minimum of two other indices. For example, the first rank of annual SPI (SPI=2.85, Fig. 8a) occurred during February 1985-February 1986, while the rank (descending order) of SCRI (Fig. 8c) and SDI (Fig. 8b) in this period was 5 and 22, respectively. The 12-month hydrological extreme flood (Fig. 8b2) occurred during 21 March 1985-20 March 1986, whereas this period ranked $13^{\text {th }}$ in annual SPI (Fig. 8b1) and first in SCRI (Fig. 8b3). The first ranked 12-month SPI (Fig. 8a1) occurred during 21 January 1994-20 January 1995, whereas this period ranked $5^{\text {th }}$ in annual SDI (Fig 8a2) and $22^{\text {nd }}$ in SCRI (Fig. 8a3). As seen, although the maximum SPI occurred in 1994, the maximum SDI was not synchronous with this period. This asynchrony between maximum hydrological and climatological extreme point was also observed for low extreme points (hydrological and metrological drought; Figs 8c-e). Again, this proves that the hydrological 
change in the Mond basin is not only due to climate variation, but also to anthropogenic activity accelerating the frequency of hydrological changes.

As shown in Fig. 3, the dry season in the Mond basin runs from late spring (May 22) until midautumn (21 November), with less than $10 \%$ of annual rainfall. Although in all months the flow rate showed a negative trend, in this period (the dry season) flow displayed an even more significant negative trend (Fig. 4). This indicates a significant reduction in base flow of the river. Furthermore, during this period the demand for irrigation is at a maximum due to high temperature. Therefore we inferred that hydrological drought during the dry season is due to increasing irrigation demand and decreasing base flow. Generally, the major source of base flow is GW. In most parts of the basin, the GW resource is extremely depleted (e.g. in Jahrom plain; Fig. 2), as the GW level showed a decline of about $18 \mathrm{~m}$ from 1999 to 2006.

\section{Discussion}

In arid and semi-arid regions, increases in irrigated agricultural land area have led to GW depletion (Jyrkama and Sykes 2007, Zaidi et al. 2015, Feike et al. 2017) and reduced runoff in streams through interactions of GW and surface water (Su 2017). Recharge-discharge processes determine the surface water availability (Sophocleous 2002), as depletion of GW weakens baseflow discharge and strengthens GW recharge, and vice versa (Sakata et al. 2016, Li et al. 2019). In arid and semi-arid regions, managed aquifer recharge structures are widely used to recharge GW and curb overdrawal (Dillon et al. 2019). Although such human interventions provide many benefits for local aquifers, they change the major characteristics of flow regime (e.g. magnitude, frequency and timing) in the downstream (Yaraghi et al. 2019). In southern Iran (Fars province), more than 500 artificial recharge basins are planned, to restore GW levels and maintain and increase agricultural areas. Large-scale use of managed aquifer recharge and 
increasing cultivated area are the main reasons for increased hydrological droughts, not the meteorological drought in the Mond basin. The negative trend in the contribution of rainfall to flow leads to a considerable reduction in dam inflow and failure to meet the major purposes of the original dam designs (e.g. Salman Farsi Dam, the largest infrastructure in the region). Continuous land and water development upstream (particularly construction of new dams, e.g. Kavar dam) have resulted in oversized downstream investment, which has failed to produce a return and is leading to exacerbation of existing water conflicts in the basin.

We introduce the term "mirage water", which is defined as the amount of allocated water for a certain purpose that has been reallocated for other purposes (Fig. 9). In regions with a high variation in observed past historical flow records, dams have been constructed to increase the overall water security of the basin. Dams that were designed based on an assumption of stationarity in inflow (Sadegh et al. 2019) are no longer meeting their purposes, due to changes in the headwaters that have led to reduced runoff (Fig. 9a). For example, in the Mond basin, the Salman Farsi dam, which was brought into operation in 2006, was designed based on data available before 1995 (Mahab Ghods 2006). However, runoff has changed considerably since 1995 due to rapid agricultural development (Fig. 9b). Therefore, for the new hydrological state of the river (Fig. 9b1), the dam is too large and is failing to fulfil some of the expected demands and goals (Fig. 9b2). This applies not only for the Salman Farsi Dam, but also for the other operational dam (Tangab) in the region and two dams under construction, namely Kavar (near the Bande-Bahman station) and Haiqer Dam (near the Dehroud gauge) (Fig. 10). A part of the expected inflow to reservoirs has been lost to upstream anthropogenic activities, and we call this lost water "mirage water" (Fig. 9b2-9b3). Mirage water is defined as the amount of water (grey part in Fig. $9 b 2$ and 9b3) that has been allocated to a certain use in the process of planning a dam (Fig. 9a1-4), but is now (or in the future) not accessible for planned purposes (Fig. 9b1-4). The role of mirage water in reservoir operation can be demonstrated by shifting the cumulative 
413 flow curve from a balance with demand (Fig. 9a4) to an unbalanced condition (Fig. 9b4). In 414 dam operation, mirage water represents water loss that results in waste of investments and decreased efficiency of the hydraulic structures designed. This needs to be considered in water resources planning activities in the upstream, such as surface water diversion for irrigation and GW recharge, particularly in arid and semi-arid regions. There are two major reasons for mirage water: natural (climate change, climate variability) and anthropogenic (lack of legislation, poor management, land-use change or increasing/uncontrolled water consumption in the headwater tributaries). Main sources of mirage water in Mond basin are the increasing cultivated area and construction of small structures for aquifer recharge and flood control (Fig. 2). In the period before dam construction, the total cultivated area in Fars province increased from 510,000 ha in 1972 to 1,193,451 ha in 2006 (Agricultural census, 1972, Agricultural census, 2006).

Mirage water could be defined for all water consumers facing water shortages due to allocation of water upstream without considering historical allocations in downstream areas. Much of the historically allocated water for consumers (e.g. agricultural, energy and environment) downstream in transboundary basins that is currently not met (Sadegh et al. 2010) can be termed mirage water, the majority of which is lost to anthropogenic interventions upstream. Examples of sectors impacted are: (1) agriculture and dam operation in Iraq after further regulation of water resources in Turkey and Syria on the Tigris and Euphrates rivers (Bremer 2016), (2) operation of the Aswan dam and agriculture in Egypt after development activities in Ethiopia on Blue Nile (Gascon 2015, Omran and Negm 2019), (3) Lake Chad in Africa, (4) the Aral Sea in central Asia and (5) Urmia lake in the Middle East after water resource development in headwaters (Torabi Haghighi and Klöve 2018, Fazel et al. 2017).

To separate changes in runoff due to land use (increased irrigation) and climate change, we used the SDI, which demonstrates variations in flow from the long-term mean (hydrological drought), and SCRI, which shows the contribution of rainfall to runoff. Increased recurrence of 
hydrological droughts (SDI) over time in comparison with recurrence of meteorological droughts (SPI) indicates land use-related hydrological changes. The SCRI could also be applied

440 for addressing mirage water, since the negative trend in SCRI clearly shows reduced contribution of rainfall to runoff and available water in the lower part of the basin. The proposed methods provide a simple tool and concept to distinguish between the reasons for hydrological change. A similar trend in SPI and SDI in the absence of any trend in SCRI indicates that the hydrological change is due to natural and climate conditions. A negative trend in SCRI and SDI in the absence of any trend in SPI indicates that the hydrological change is due to anthropogenic reasons (as seen here for the Mond basin). A negative trend in SCRI, SPI and SDI indicates that the hydrological change is due to a combination of natural and anthropogenic causes. Interpretation of SPI, SDI and SCRI simultaneously, alongside the mirage water concept, could help to allocate water resources in an optimal and realistic way.

We acknowledge that SDI is associated with well-documented uncertainties (e.g. Shukla and Wood 2008, Vicente-Serrano et al. 2012), and these uncertainties could impact the results of this work. Our new index, SCRI, is based on the contribution of rainfall to runoff. In calculating the contribution of rainfall to runoff, the main uncertainties could relate to the amount of rainfall (Eq. 2). In this regard, it was noted that high uncertainty arose when we used the amount of rainfall at the closest metrological station (point rainfall) to the discharge gauge, as this amount does not properly demonstrate the actual amount of rainfall that contributed to runoff. To reduce this uncertainty, we calculated the graded rainfall for sub-basins of each hydrological gauge by using all available meteorological stations inside or outside the sub-basin.

\section{Conclusions}

In arid and semi-arid regions, the regional economy relies on agriculture with a high dependency on groundwater $(\mathrm{GW})$. With declining GW levels, managed aquifer recharge is used as a method to increase recharge and water storage for irrigation. Increasing area of 
irrigated agriculture significantly changes annual runoff in the basin, as more water is transpired through crops. This results in considerable uncertainty in planning and operation of dams and reservoirs designed based on the assumptions of runoff stationarity and former reservoir inflows. To better account for the loss in available water at the basin scale due to upstream developments, we suggest the term "mirage water" as a means to communicate to decision makers expected inflows to dams or previously allocated water for a given purpose that are not currently met. Mirage water is defined as the amount of water allocated for a specific purpose in the downstream area that has since been reallocated for new purposes upstream and is now (or in the future) not available for the original planned purposes. An increasing amount of mirage water in a water resources system could destabilise supply and demand balance and create conflicts. We developed a novel index (Standardized Rainfall to Runoff Index, SCRI) to show the variation in rainfall contribution to runoff, which can help to quantify mirage water. A negative trend in SCRI indicates reduced contribution of rainfall to runoff and available water in lower parts of the basin. By interpreting SCRI alongside two well-known drought indices, Standardized Precipitation Index (SPI) and Standardized Discharge Index (SDI), we were able to assess the causes of hydrological alteration as anthropogenic, natural or a combination of both. Beyond its novel technical content, this study prevents important new information on mismanagement of water resources in arid regions.

\section{References}

Al-Senafy, M. and Abraham, J., 2004. Vulnerability of groundwater resources from agricultural activities in southern Kuwait. Agricultural Water Management. 64, 1-15.

Ambast, S.K., Tyagi, N.K. and Raul, S.K., 2006. Management of declining groundwater in the Trans Indo-Gangetic Plain (India): Some options. Agricultural Water Management, 82, 279296.

Angelidis P., Maris F., Kotsovinos N. and Hrissanthou V., 2012. Computation of drought index SPI with alternative distribution functions. Water Resources Management 26, 2453-2473 
Azari Dehkordi, M., 2011. Water resources atlas report: Mond Basin. Parab Fars Consoulting Engineering Co.

Bremer, N.C., 2016. Transboundary environmental impact assessment of large dams in the Euphrates-Tigris Region: An analysis of international law binding Iran, Iraq, Syria and Turkey. Review of European, Comparative and International Environmental Law 25(1), 92-106.

Biswas, A.K., 2007. Water as a human right in the MENA region: Challenges and opportunities. Int.J.Water Resour.Dev. 23, 209-225.

Dillon, P., et al., 2019. Sixty years of global progress in managed aquifer recharge.

Hydrogeology Journal 27(1), 1-30.

Edwards, D.C. and McKee, T.B., 1997. Characteristics of 20th century drought in the United States at multiple time scales. Characteristics of 20th Century Drought in the United States at Multiple Time Scales. Fort Collins, Colorado, Department of Atmospheric Science, Colorado State University. Available from: https://mountainscholar.org/handle/10217/170176 (Accessed 26 Jul. 2019)

Fazel, N., Torabi Haghighi, A and Kløve, B., 2017. Analysis of land use and climate change impacts by comparing river flow records for headwaters and lowland reaches. Global and planetary change. $158,47-56$.

Farahmand A. and Aghakouchak A., 2015. A Generalized Framework for Deriving Nonparametric Standardized Drought Indicators, Advances in Water Resources, 76, 140-145.

Hao Z. et al., 2014. Global Integrated Drought Monitoring and Prediction System, Scientific Data, 1:140001, 1-10.

GASCON, A., 2015. Battles on the Nile: A war for water? Bulletin d'Association de Geographes Francais 92(2), pp. 154-166.

Gilbert, R.O., 1987, Statistical Methods for Environmental Pollution Monitoring. Van Gilbert, R.O., Van Nostrand Reinhold, ISBN 0-471-28878-0, New York.

Giordano, M. and Villholth, K.G., 2007. The Agricultural Groundwater Revolution: Opportunities and Threats to Development, CABI. pp. 1-419.

Hojjati, M.H. and Boustani, F., 2010. An assessment of groundwater crisis in Iran case study: Fars province. World Academy of Science, Engineering and Technology. 46, 475-479.

Hughes, B.L. and Saunders, M.A., 2002. A drought climatology for Europe. International Journal of Climatology, 22,1571-1592.

Irannezhad, M. et al., 2015. Variability in dryness and wetness in central Finland and the role of teleconnection patterns Theoretical and Applied Climatology, 122 (3-4), pp. 471-486.

Jyrkama, M.I. and Sykes, J.F., 2007. The impact of climate change on spatially varying groundwater recharge in the Grand River watershed (Ontario). Journal of Hydrology 338(3-4), 237-250. 
Kendall, M.G., 1975. Rank Correlation Methods. Griffin.

Mahab Ghods, 2006. Salman farsi dam and irrigation's environmental impact assessment. Mahab Ghods, 2082810-2040, 1-25.

MAJ, 2017. Agriculture census 2016. The Ministry of Agriculture-Jahad 1, 20-100. https://www.maj.ir/Dorsapax/userfiles/Sub65/Amarnamehj1-95-96-site.pdf (available online: 21.07.2019).

MAJ, 2006. Agriculture census 2006. The Ministry of Agriculture-Jahad 1, 20-100. https://www.maj.ir/Dorsapax/userfiles/Sub65/amarnamehJ1-85-86.pdf (available online: 21.07.2019)

Mann, H.B., 1945. Nonparametric tests against trend. Econometrica, 13, 245-259.

Mallakpour, I., AghaKouchak, A. and Sadegh, M., 2019. Climate-induced changes in the risk of hydrological failure of major dams in California. Geophysical Research Letters 46(4), pp.2130-2139.

MATHWORKS, 2019-last update, Interpoloin Scattered Data, (available online 16.08.2019). https://se.mathworks.com/help/matlab/math/interpolating-scattered-data.html

McKee, T.B., Doesken, N.J. and Kleist, J., 1995. Drought monitoring with multiple time scales. 9th Conference on Applied Climatology, 233-236.

McKee, T.B., Doesken, N.J. and Kleist, J., 1993. The relationship of drought frequency and duration to time scales. Eighth Conference on Applied Climatology, 179-184.

Molina, J.-L. et al., 2011. Integrated Assessment of the European WFD Implementation in Extremely Overexploited Aquifers Through Participatory Modelling. Water Resources Management 25, 3343-3370.

Montaseri, M., Amirataee, B. and Nawaz, R., 2017. A Monte Carlo Simulation-Based Approach to Evaluate the Performance of three Meteorological Drought Indices in Northwest of Iran. Water Resources Management. 31, 1323-1342.

Morris, B.L., et al., 2003. Groundwater and Its Susceptibility to Degradation: A Global Assessment of the Problem and Options for Management. Assessment Report Series. (RS. 033) $3,126$.

Nikouei, A. and Ward, F.A., 2013. Pricing irrigation water for drought adaptation in Iran. Journal of Hydrology. 503, 29-46.

Omran, E.-.E. and Negm, A., 2019. Environmental mpacts of the GERD Project on Egypt's Aswan High Dam Lake and Mitigation and Adaptation Options. ?????????

Oweis, T.Y., 2005. The Role of Water Harvesting and Supplemental Irrigation in Coping with Water Scarcity and Drought in the Dry Areas, in: Wilhite, D.A., (Ed.), Drought and Water Crises Science, Technology, and Management Issues. Boca Raton, Taylor \& Francis, 191-213. 
Ruprez-Moreno, C., et al. 2017. Sustainability of irrigated agriculture with overexploited aquifers: The case of Segura basin (SE, Spain). Agriculture Water Management. 182, 67-76.

Sadegh, M., Mahjouri, N. and Kerachian, R., 2010. Optimal inter-basin water allocation using crisp and fuzzy Shapley games. Water Resources Management. 24, 2291-2310.

Sadegh, M. et al., 2018. Multihazard scenarios for analysis of compound extreme events. Geophysical Research Letters 45(11), 5470-5480.

Sadegh, M. et al., 2019. A multi-model nonstationary rainfall-runoff modeling framework: Analysis and toolbox. Water Resources Management 33(9), 2011-3024.

SCI, 1973. Agricultural census 1972. The Statistical Centre of Iran, 12(3), pp. 238-60.

SCI, 2015. Agricultural census 2014. The Statistical Centre of Iran, 12(3), 25-65.

https://www.amar.org.ir/Portals/0/keshavarzi93/results/agri93-99.pdf (available online 21.7.2019)

Soil and Water Subgroup, 2004. Proposal for artificial recharge projects in order to flood control to improve the quality and quantity of groundwater resources and reducing water crisis. Ministry of Jahade-Keshavarzi.

Soltani, G. and Saboohi, M., 2008. Economic and social impacts of groundwater overdraft: the case of Iran. 15th ERF annual conference, 1-16.

S. Shukla, A. and W. Wood, 2008. Use of a standardized runoff index for characterizing hydrologic drought, Geophysical Research Letters, 35, 1-7.

Thom, H.C.S., 1966. Some methods of climatological analysis. Some Methods of Climatological Analysis.

Torabi Haghighi, A., Kløve, B., 2017. Design of environmental flow regimes to maintain lakes and wetlands in regions with high seasonal irrigation demand. Ecological Engineering. 100, 120-129.

Torabi Haghighi, A., et al., 2018. Analysis of effective environmental flow release strategies for Lake Urmia restoration. Water Resources Management 32, 3595-3609.

Van Camp, M., Radfar, M. and Walraevens, K., 2010. Assessment of groundwater storage depletion by overexploitation using simple indicators in an irrigated closed aquifer basin in Iran. Agricultural Water Management. 97, 1876-1886.

Vicente-Serrano, S.M., et al., 2011. Accurate computation of a streamflow drought index. Journal of Hydrologic Engineering, 17, 318-332.

Yaraghi, N. et al. 2019. Impact of managed aquifer recharge structure on river flow regimes in arid and semi-arid climates. Science of the Total Environment 675, 429-438.

Yu, Y. et al., 2017. Agricultural water allocation strategies along the oasis of Tarim River in Northwest China. Agricultural Water Management. 187, 24-36. 
597 ZAIDI, F.K. et al., 2015. Identification of potential artificial groundwater recharge zones in 598 Northwestern Saudi Arabia using GIS and Boolean logic. Journal of African Earth Sciences 599 111, 156-169.

600 Zaki, N.A., et al. 2019. An index-based approach to assess the water availability for irrigated 601 agriculture in sub-Saharan Africa. Water (Switzerland), 11(7), 1456.

602

603

Table 1. Different categories of climatological conditions based on standard precipitation

604 index (SPI) value

\begin{tabular}{llll} 
Category & Range of SPI & Category & Range of SPI \\
\hline Extremely wet & More than $2.00^{*}$ & Extremely wet & More than 2.00 \\
Very wet & $1.50-1.99^{*}$ & Very wet & $1.50-1.99$ \\
Moderately wet & $1.00-1.49^{*}$ & Moderately wet & $1.00-1.49$ \\
Mildly wet & $0.00-0.99^{*}$ & Mildly wet & $0.50-0.99$ \\
& & Normal & $-0.50-0.50$ \\
Mild drought & $-0.99-0.00^{* * * *}$ & Mild drought & $-0.99--0.50$ \\
Moderate drought & $-1.49--1.00^{* * * *}$ & Moderate drought & $-1.49--1.00$ \\
Severe drought & $-2.00--1.50^{* * * *}$ & Severe drought & $-2.00--1.50$ \\
Extreme drought & Less than $-2.00^{*, * *}$ & Extreme drought & Less than -2.00 \\
\hline
\end{tabular}
605 

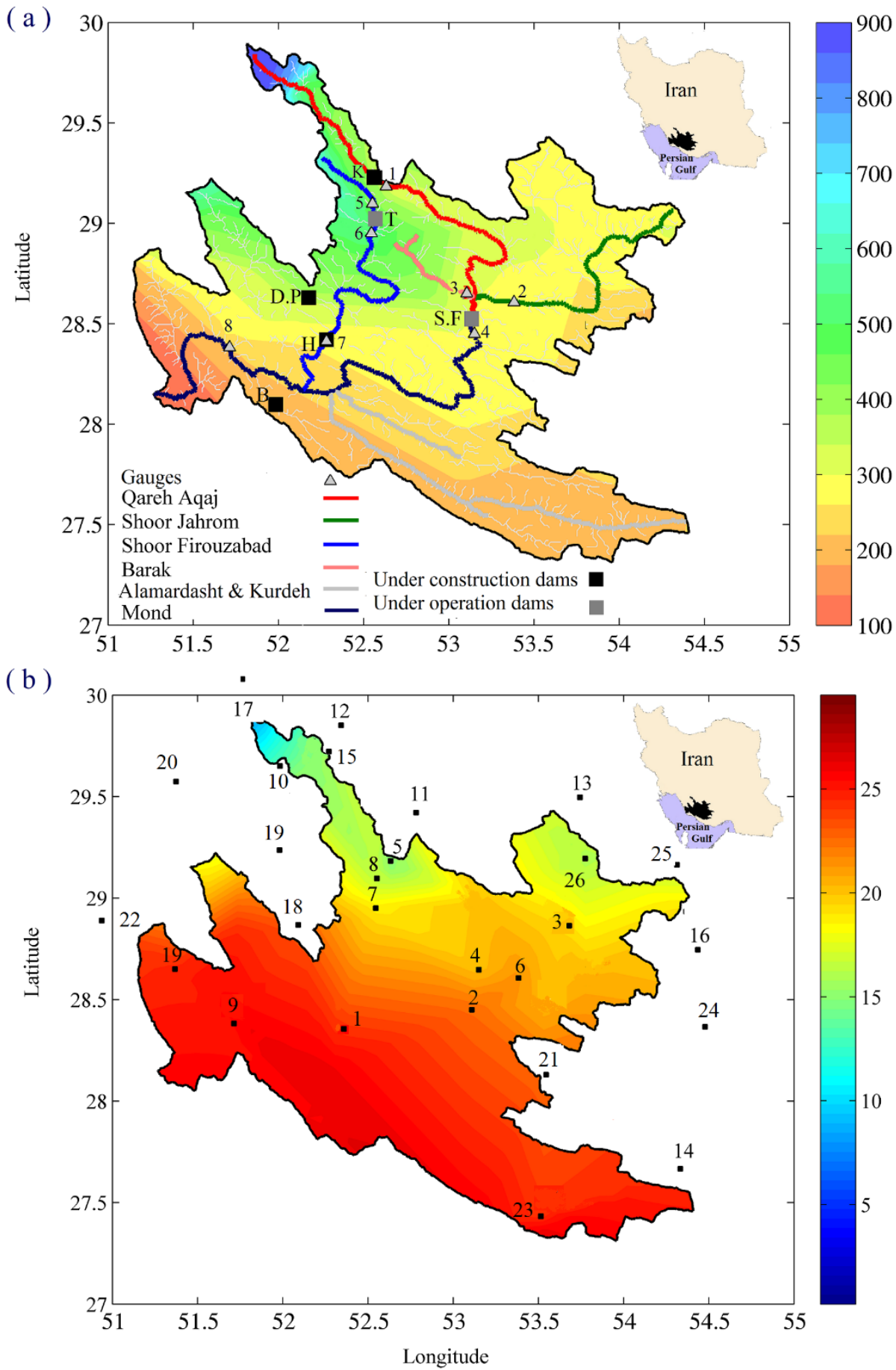

Fig 1. Mond basin: a) spatial distribution of annual rainfall ( $\mathrm{mm}$ ), rivers, location of dams and discharge flow measuring gauges, b) distribution of mean annual temperature $\left({ }^{\circ} \mathrm{C}\right)$ and location of 26 climate stations, K: Kavar dam, S.F: Salman Farsi dam, T: Tangab Dam, H: Haiqer dam, D.P: Dashte Plang dam and B: Baghan Dam. Gauge stations 1: Bande-Bahman, 2: Hakkan, 3:Barak, 4:Tange-Karzin, 5: Hanifaghan, 6: Tangab, 7: Dehroud and 8: Ghantareh. The name of rainfall station in supplementary material. 

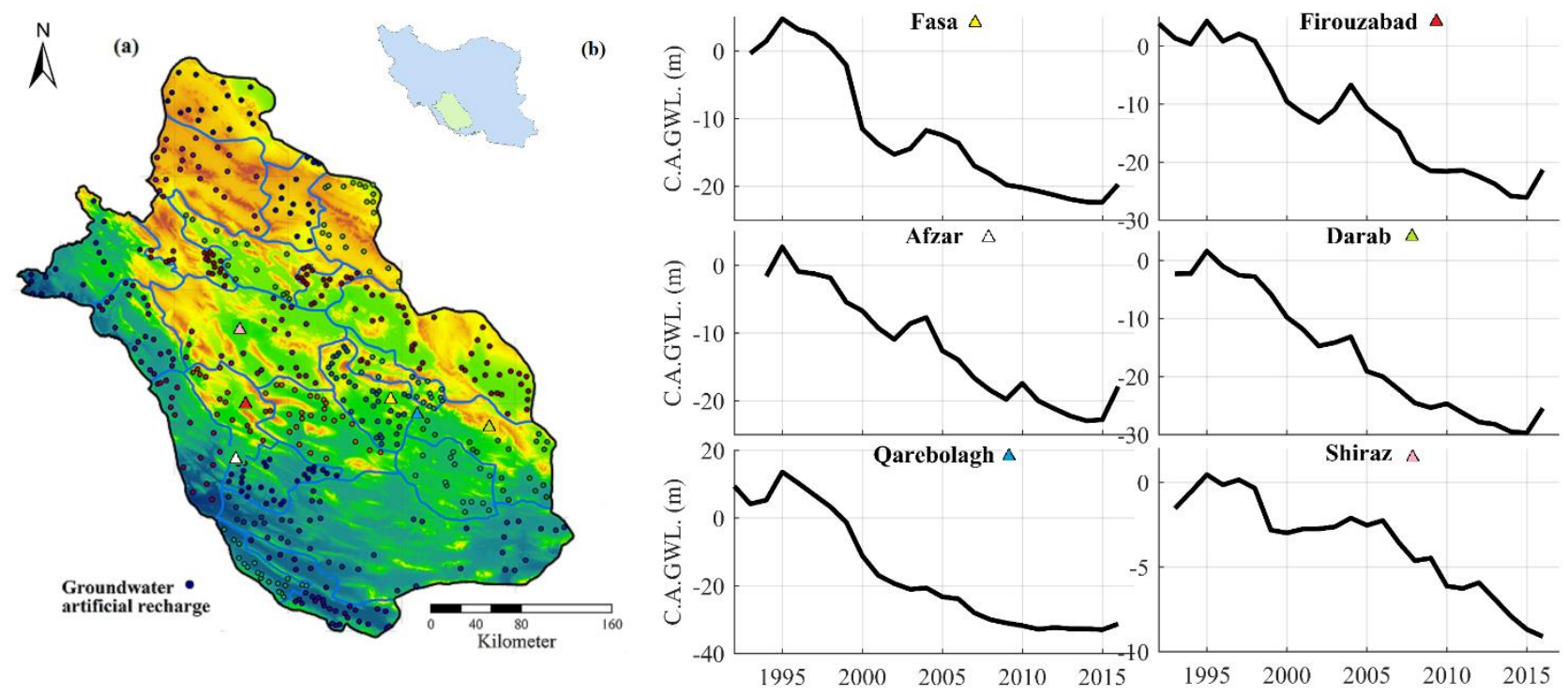

618 Fig. 2. a) Map of approximate location of constructed or planned artificial groundwater (GW) recharge structures in Fars province, b) Decline in groundwater level in six plains as sample area in Fars. Note: in (a), the points are randomly distributed based on the reported/planned location. 

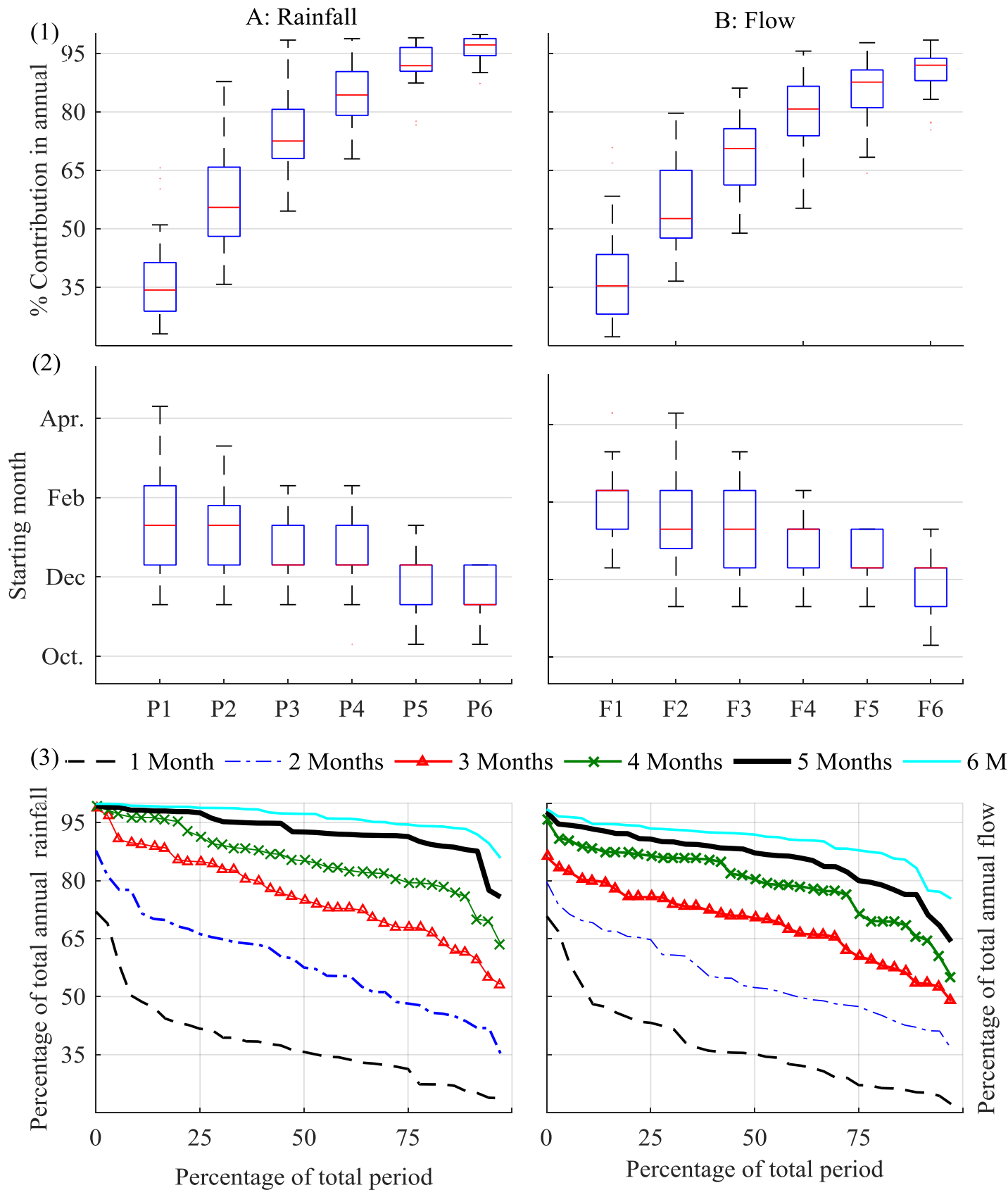

623 Fig. 3. Temporal characteristics of contribution (\%) of 1-6 months Rainfall (A) and flow (B) in annual,: 1) contribution of wet period to annual rainfall (P1-P6) and flow (F1-F6) during 1-6 months. 2) boxplot for starting month of wet period which includes maximum rainfall (P1-P6) and flow (F1-F6) during 16 months. 3) Percentage of total period (from 1971-2006) in which maximum rainfall and flow occurred during different time sequences (1- 6 months). 


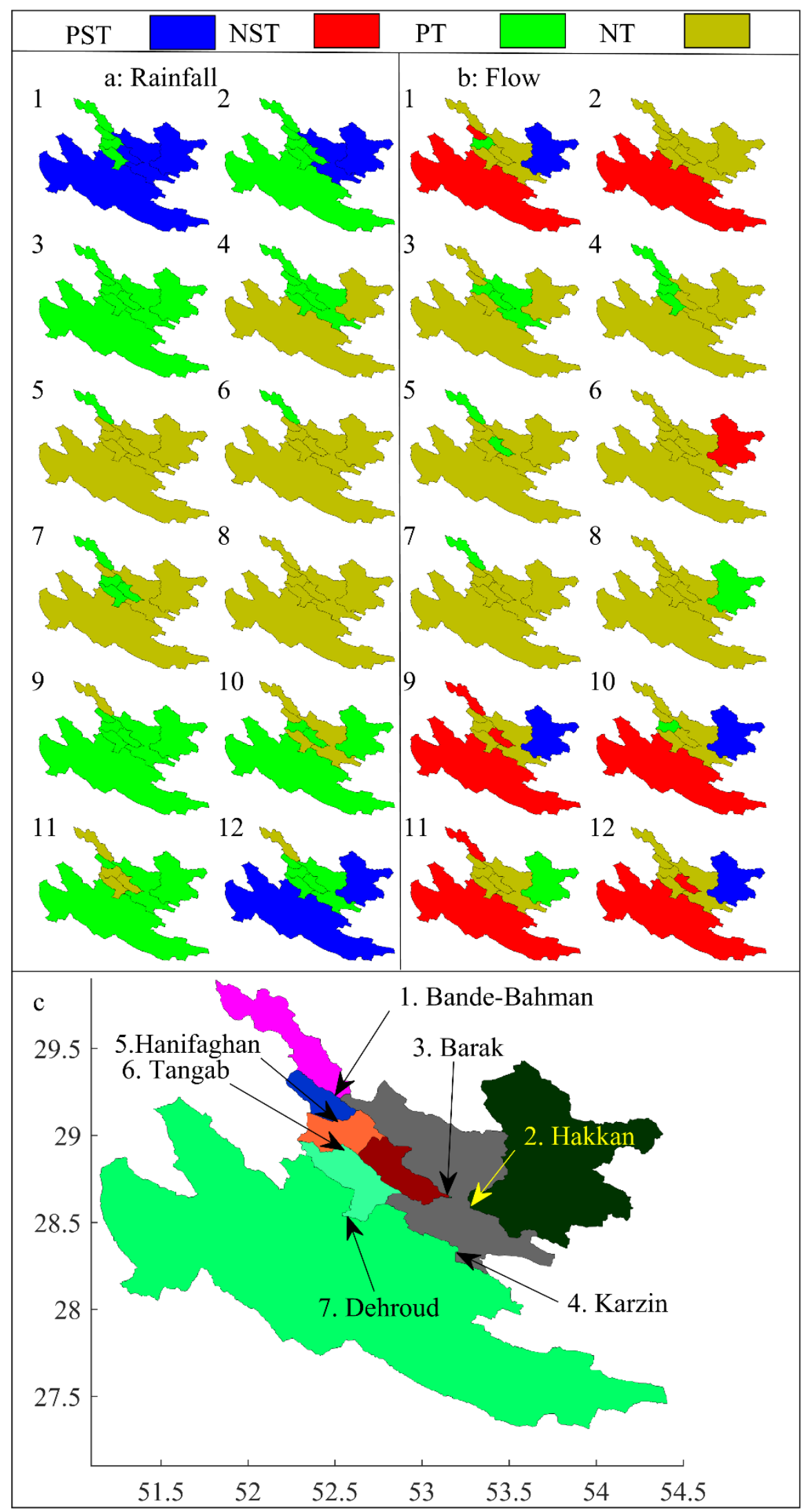

Fig. 4. Spatio-temporal trend of monthly a) rainfall and b) flow in different sub-basins, 1-12 indicate $\leq+0.05)$, PT: positive tendency $\left(\mathrm{P}_{\mathrm{val}}>+0.05\right)$, NT: negative tendency $\left.0.00 \geq \mathrm{P}_{\mathrm{val}} \geq-0.05\right)$. 

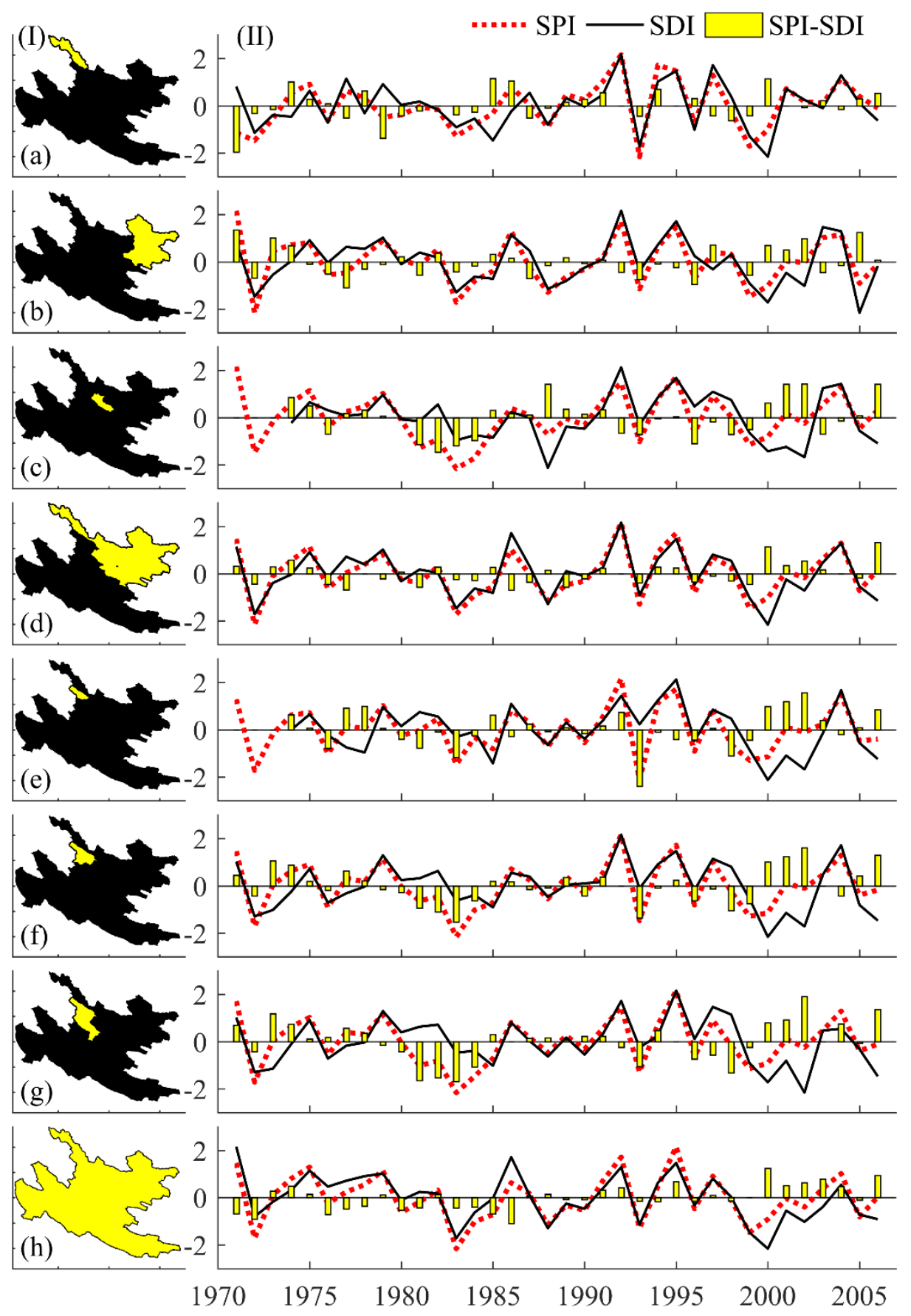

Fig. 5. Spatio-Temporal hydrological (SDI) and metrological (SPI) droughts in the Mond river basin. The years defined based on the Iranian hydrological year, which runs from October- September, a-h shows the sub-basins of Bande-Bahman (Near Kavar dam), Hakkan, Barak, Tange-Karzin (Salman Farsi 


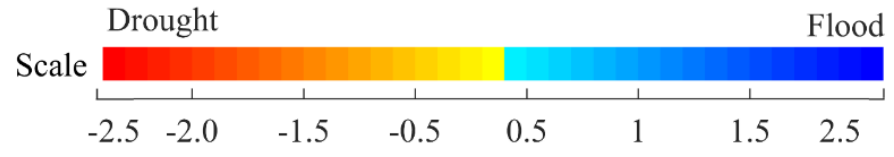

(a)

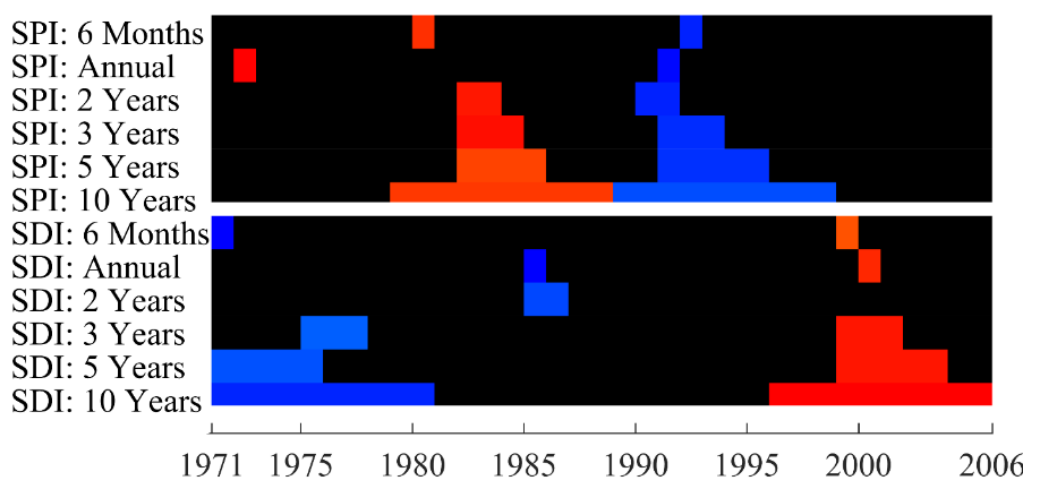

(b)

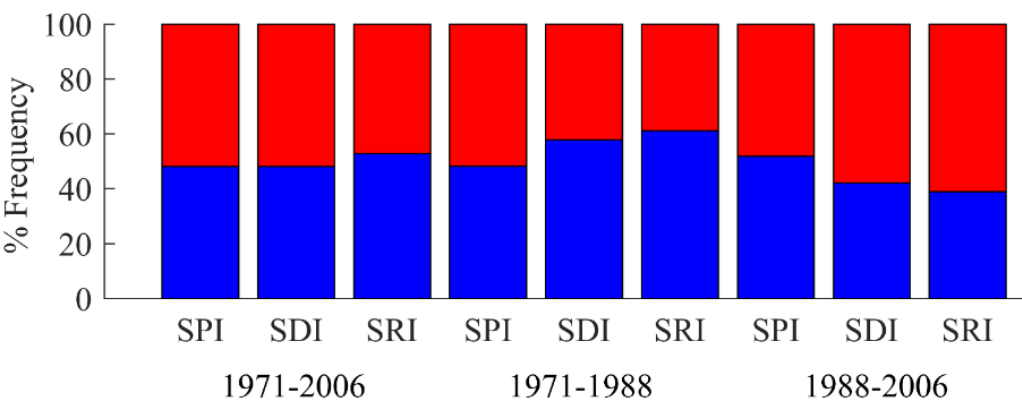

641 Fig. 6. Comparison of long-term climatological and hydrological variation throughout the Mond basin, 642 a) the temporal variation of extreme part1: SPI, part b: SDI, b) temporal comparison of SPI, SDI and 643 SRI based on the discharge at Qantareh gauge station and mean rainfall overall in the basin. Red and 644 blue indicate negative (drought) and positive (flood) sign, respectively, for SPI, SDI and SRI. 

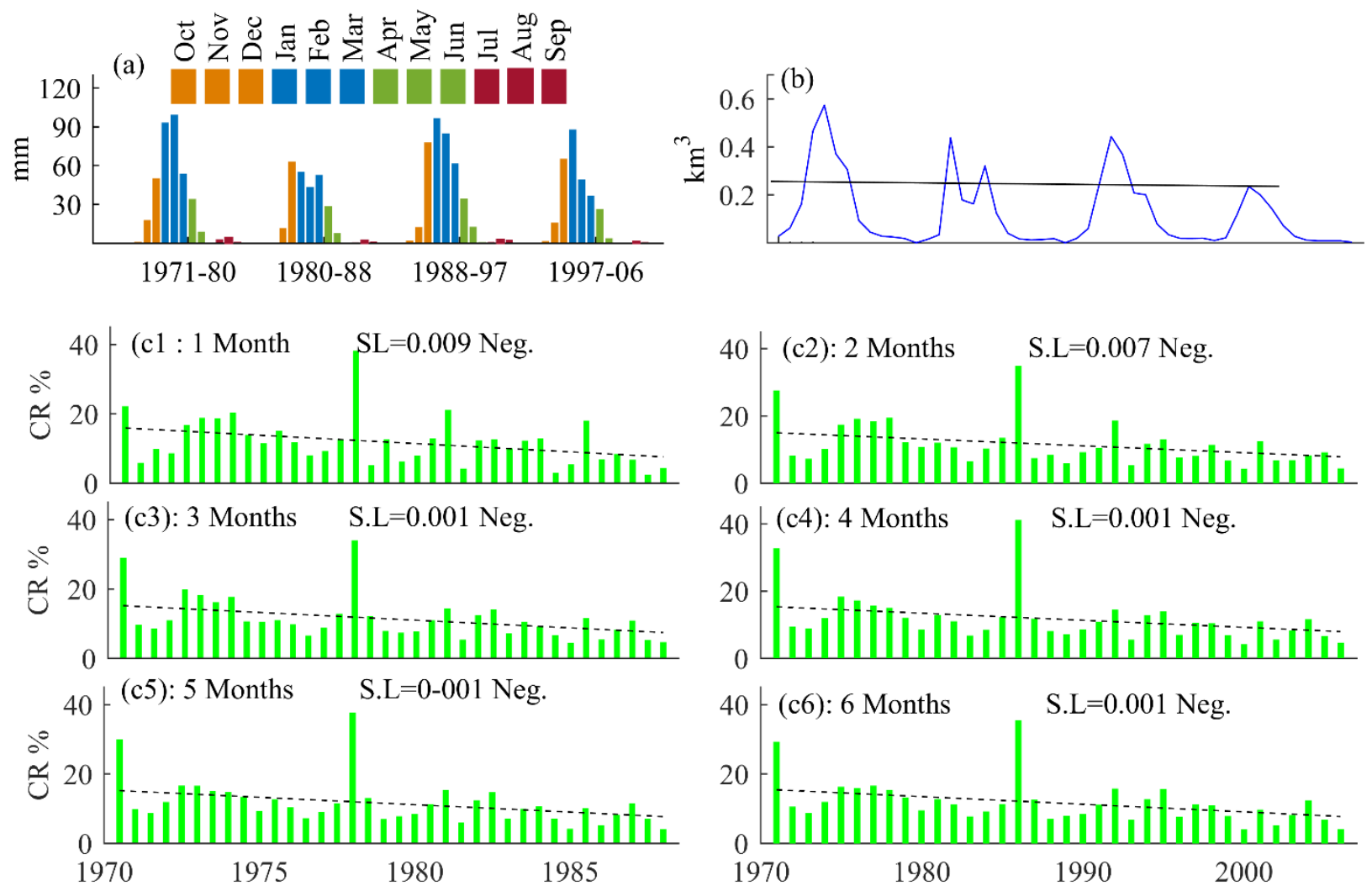

647 Fig. 7. Contribution of rainfall to flow at Qantareh gauge, a and b) mean monthly rainfall and volume of flow during different periods, c1-6) trend of contribution of rainfall to runoff (R) for periods 1-6 months. S.L.: significant level, Neg: negative trend. 


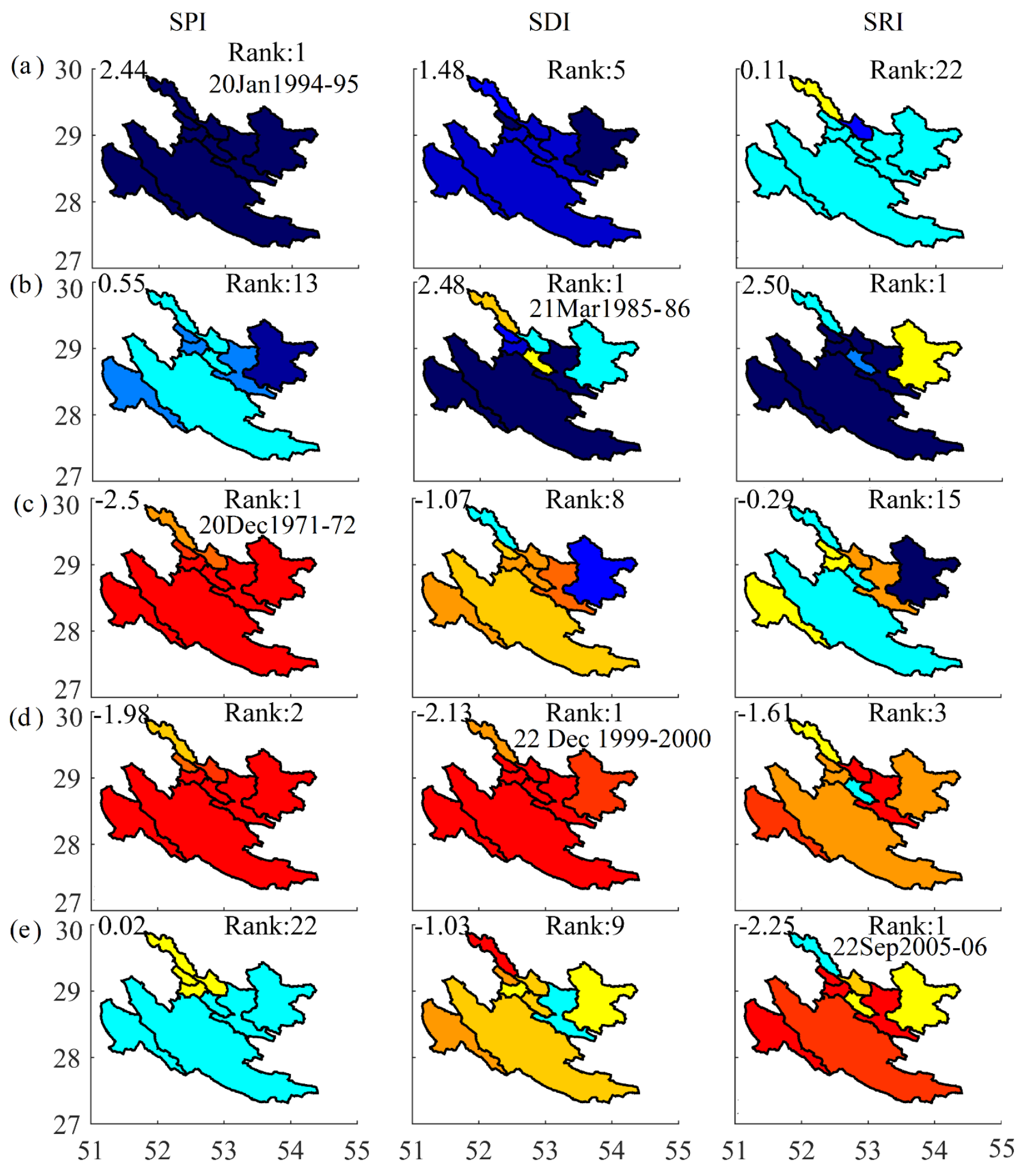

651

652 Fig. 8. Extreme 12-month events for maximum a) SPI, b) SDI and SRI, and for minimum c) 653 SPI, d) SDI and e) SRI. 
(a1)

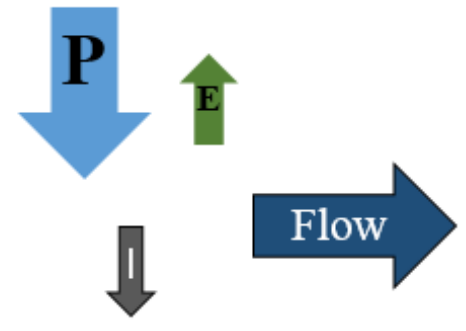

(a2)

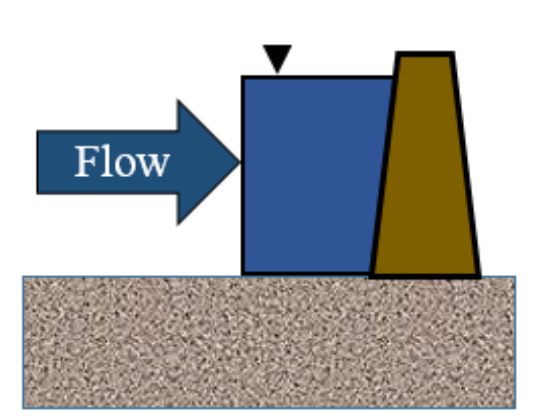

(a3)

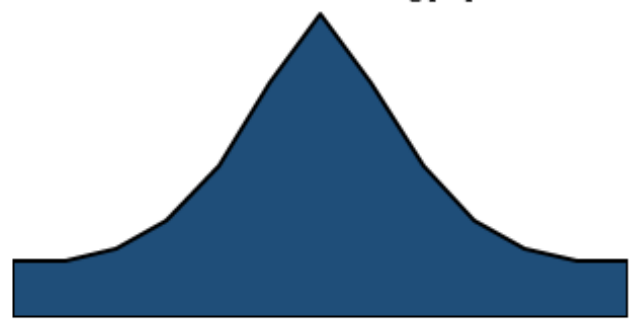

(a4)

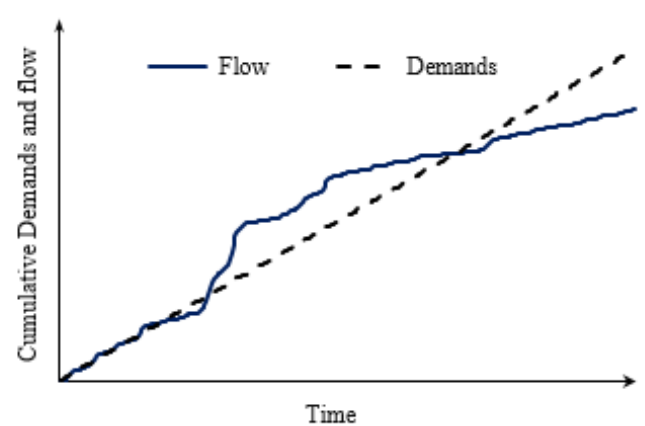

(b1)

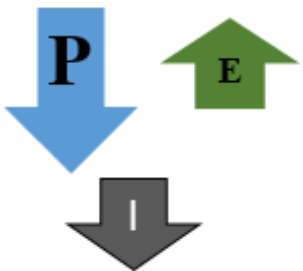

Flow

(b2)

Planned purposes

\begin{tabular}{|l|}
\hline Goal $\mathrm{n}$ \\
\hline$\ldots . . .$. \\
\hline$\ldots . . .$. \\
\hline Goal 3 \\
\hline Goal 2 \\
\hline Goal 1 \\
\hline
\end{tabular}

(b3)

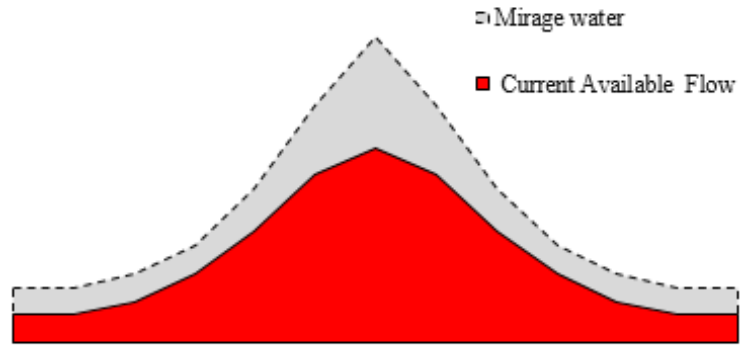

(b4)
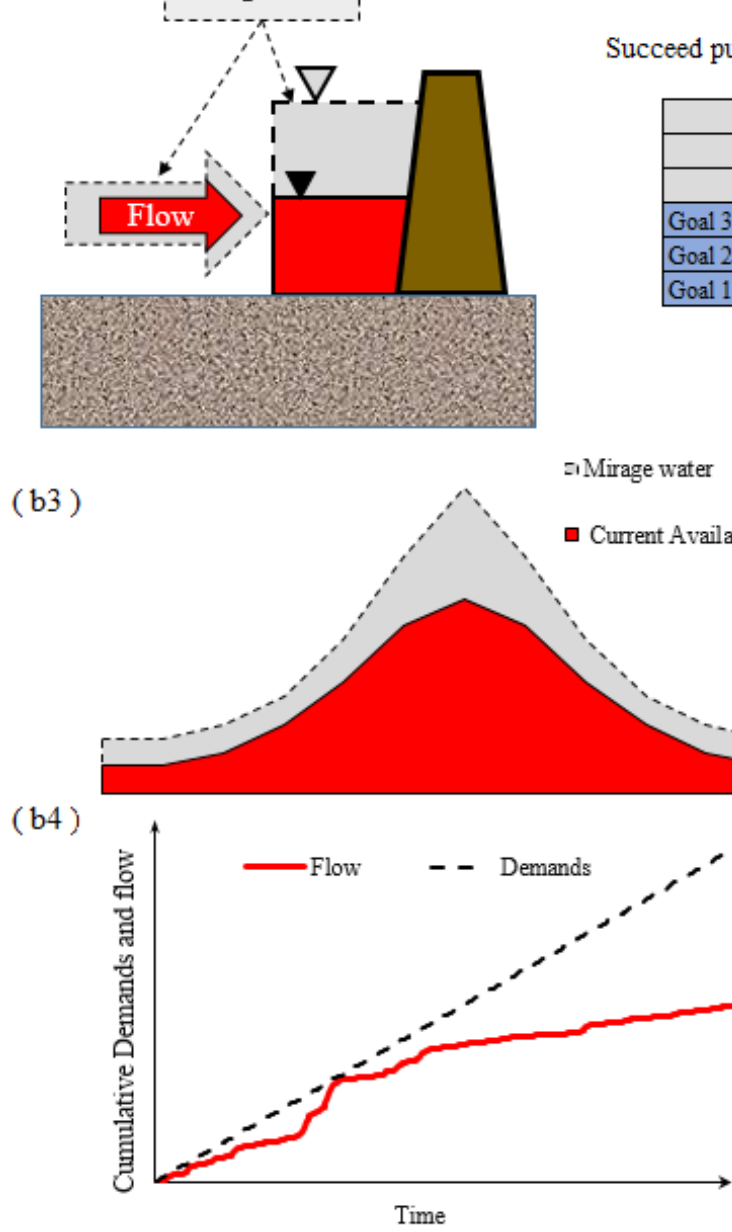

Succeed purposes

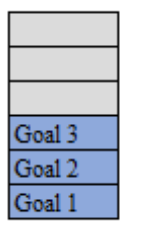

660 Fig. 9. Water resources components a) before (design period) and b) after (operation period) upstream modification and schematic of the 'mirage water' concept, 1) water balance elements, 2-3) dam system configuration 4) cumulative flow and demand curve, P: precipitation, E: evapotranspiration, I: infiltration. 
(1)

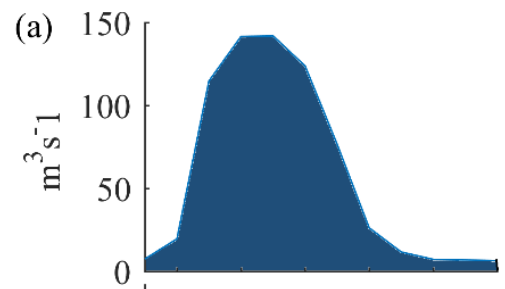

(b)

(c)
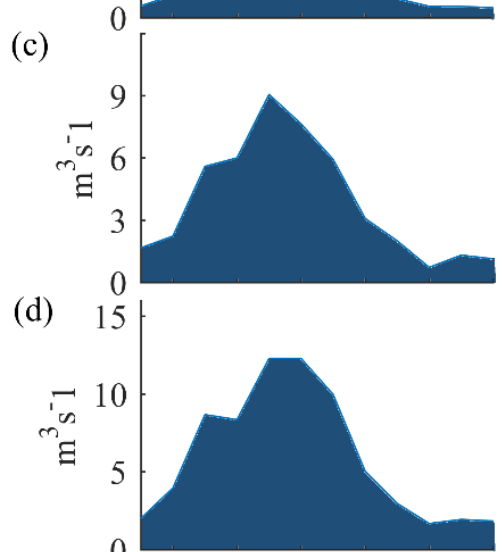

(e)

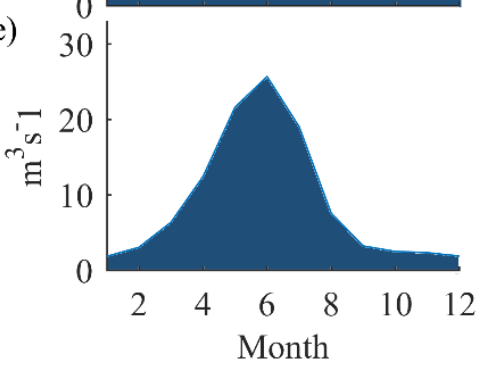

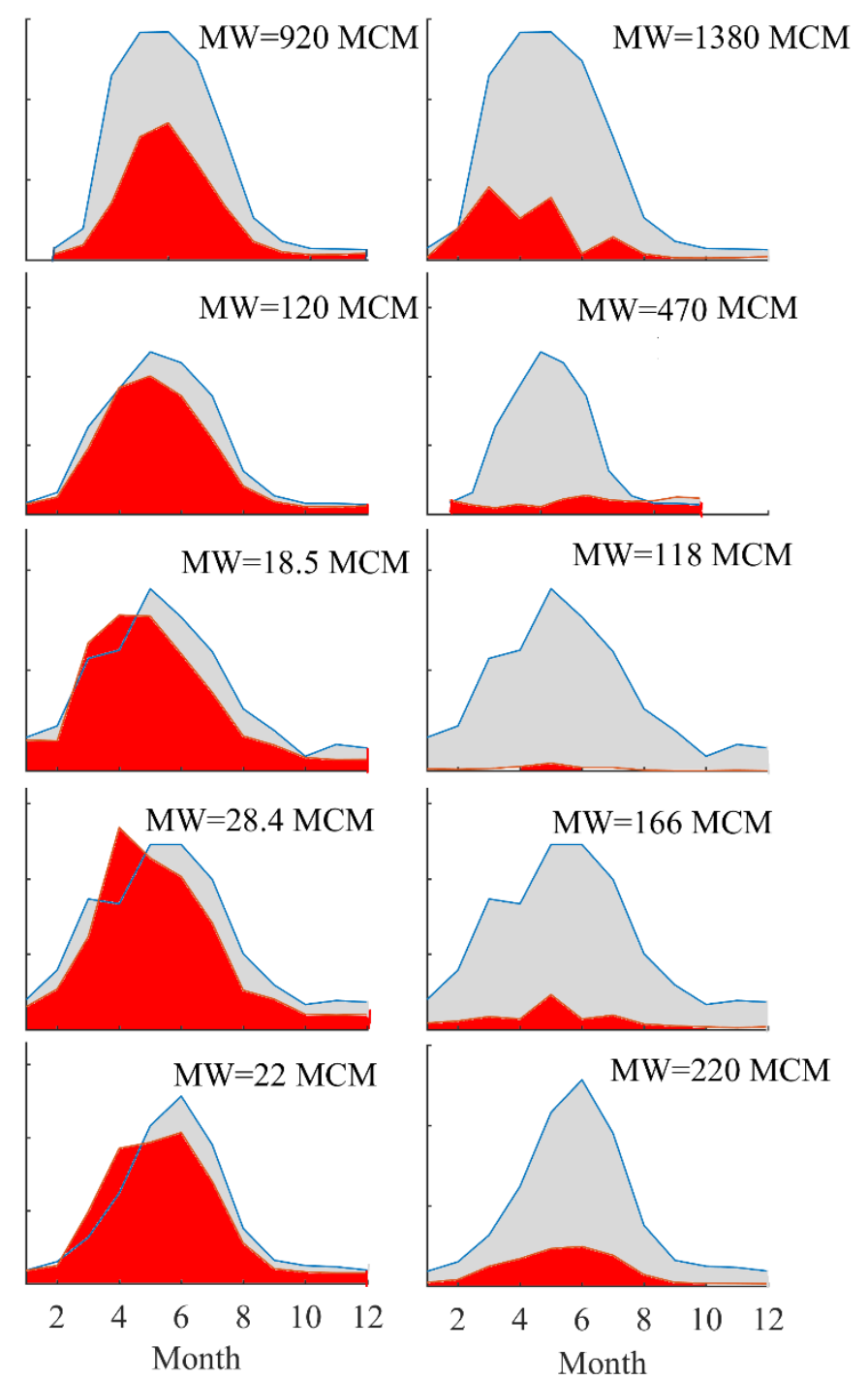

665

666

670

671

672

673
(2)

(3)

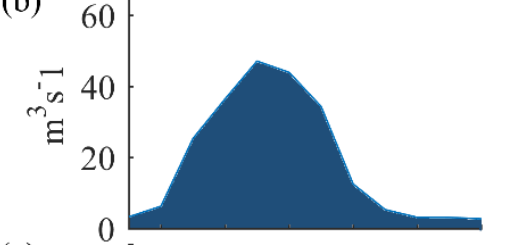

Fig 10. Mirage water in important points of Mond basin a-e at Ghantareh (outlet of basin), Tange- Karzin (Salman Farsi dam), Tangab Dam, Haiqer Dam and Kavar Dam. 1: monthly flow for period 1971-1995, 2 Altered flow (1996-2006) before impounding Tangab and Salman dam, 3: 2007-2014 before opening of Kavar and Haiqer dam. 